\title{
Pharmacokinetic Comparison and Bioequivalence of a New Generic Formulation of Lenalidomide 25 mg Capsules versus Revlimid in Healthy Volunteers under Fasting Conditions
}

Dalia Jawhari, Mahmoud Alswisi, Mahmoud Ghannam* and Jamil Al-Halman

Hikma Pharmaceuticals, Amman, Jordan

\begin{abstract}
Lenalidomide is an immunomodulatory agent with direct antiproliferative, proapoptotic, and antiangiogenic effects, combined with long-term immunostimulatory effects which improve both cellular and humoral immune function. Lenalidomide is indicated for the treatment of patients with multiple myeloma, who are previously untreated and not eligible for transplant. Lenalidomide has dual effects, involving both direct tumoricidal properties and immunomodulatory activity.
\end{abstract}

A single centre, open-label, single-dose, randomized, two-period, two-treatment, two sequence, crossover, comparative bioavailability study was conducted in 24 healthy volunteers to compare pharmacokinetics profile of a new lenalidomide generic formulation (lenalidomide capsules $25 \mathrm{mg}$, Hikma Pharmaceuticals) with those of the reference product (Revlimid, Celgene Gmbh, United Kingdom). The study was conducted at Pharma Medical Research Inc. (Canada) in accordance with Good Clinical Practices and the applicable regulatory requirements.

One capsule of each formulation was administered with $240 \mathrm{~mL}$ of water after a $10 \mathrm{hr}$ overnight fast. In each study period, eighteen (18) blood samples were collected by venepuncture in pre-cooled Vacutainers containing EDTA. First blood sample $(2 \times 6 \mathrm{~mL})$ was collected prior to drug administration while the others $(1 \times 6 \mathrm{~mL}$ each) were collected at $0.167,0.333,0.5,0.75,1,1.25,1.5,1.75,2,2.5,3,4,6,8,10,12$ and $14 \mathrm{~h}$ after drug administration. The drug product administrations were separated by a washout period of 7 calendar days.

Plasma samples were analyzed for lenalidomide by a validated LC/MS/MS method. For a $25 \mathrm{mg}$ dose of lenalidomide, the analytical range was approximately $2 \mathrm{ng} / \mathrm{mL}$ to $1000 \mathrm{ng} / \mathrm{mL}$. Descriptive statistics were used to summarize adverse events (AE), safety results and demographic variables (age, height, weight and BMI)

The main pharmacokinetic parameters of interest for this study were $C_{\max }, A C_{0-T}$ and $A U C_{0-\infty}$. Other parameters such as $\mathrm{T}_{\text {max }}, \mathrm{AUC}_{\mathrm{T} / \infty}, \mathrm{K}_{\mathrm{el}}$ and $\mathrm{T}_{1 / 2 \mathrm{el}}$ were provided for information purposes only. The natural logarithmic transformation of $C_{\max }, A \cup C_{0-T}$ and $A U C_{0-\infty}$ was used for all statistical inference. The mean (CV \%) of $C_{\text {max }}, A U C_{0-T}$ and $A U C_{0-\infty}$ for lenalidomide were $467.1 \mathrm{ng} / \mathrm{mL}(21 \%), 1395.4 \mathrm{ng} . \mathrm{h} / \mathrm{mL}(12 \%)$ and $1448.7 \mathrm{ng} . \mathrm{h} / \mathrm{mL}(13 \%)$ versus $454.3 \mathrm{ng} / \mathrm{mL}$ (27\%), $1396.3 \mathrm{ng} \cdot \mathrm{h} / \mathrm{mL}(13 \%)$ and $1448.1 \mathrm{ng} \cdot \mathrm{h} / \mathrm{mL}(13 \%)$ for Revlimid. The $90 \%$ confidence intervals of $\mathrm{C}_{\max }, \mathrm{AUC}_{0-\mathrm{T}}$ and $A \cup C_{0-\infty}$ for lenalidomide were $(93.7 \%-116.3 \%),(97.8 \%-102.3 \%)$ and $(97.9 \%-102.4 \%)$ respectively. The ratio of the geometric LS means for the test to reference $\mathrm{C}_{\text {max }}, \mathrm{AUC}_{0-\mathrm{T}}$ and $\mathrm{AUC}_{0-\infty}$ were $104.4 \%, 100.0 \%$ and $100.1 \%$ respectively.

The analysis of variance (ANOVA) did not show any significant difference between the two formulations and $90 \%$ confidence intervals $(\mathrm{Cl})$ fell within the acceptable range for bioequivalence. Based on these statistical outcomes it was concluded that the two formulations of lenalidomide exhibited comparable pharmacokinetic profiles.

Keywords: Lenalidomide; Bioequivalence; Pharmacokinetics; Immunomodulatory

\section{Introduction}

Lenalidomide is an immunomodulatory agent with direct antiproliferative [1], proapoptotic [2], and antiangiogenic effects [3], combined with long-term immunostimulatory effects which improve both cellular and humoral immune function [4]. Lenalidomide is a derivative of thalidomide, developed by modification of the structural backbone of thalidomide [5], it has more potent antitumor activity compared with thalidomide [6] with improved toxicity profile [7]. Lenalidomide has an asymmetric carbon atom and can exist as the optically active forms $\mathrm{S}(-)$ and $\mathrm{R}(+)$, and is produced as a racemic mixture with a net optical rotation of zero [8].

Lenalidomide, 3-(4-amino-1-oxo-1,3-dihydro-2H-isoindol-2-yl) piperidine-2,6-dione, is a synthetic glutamic acid derivative [9]. It has the following chemical structure:

*Corresponding author: Mahmoud Ghannam, Senior Project Leader, Hikma Pharmaceuticals, Amman, Jordan, Tel: + $962788685121 ;$ Fax: + 962 6 4023917; E-mail: mghannam@hikma.com

Received July 06, 2016; Accepted July 30, 2016; Published August 12, 2016

Citation: Jawhari D, Alswisi M, Ghannam M, Al-Halman J (2016) Pharmacokinetic Comparison and Bioequivalence of a New Generic Formulation of Lenalidomide 25 mg Capsules versus Revlimid in Healthy Volunteers under Fasting Conditions. J Bioequiv Availab 8: 214-219. doi: 10.4172/jbb.1000298

Copyright: @ 2016 Jawhari D, et al. This is an open-access article distributed under the terms of the Creative Commons Attribution License, which permits unrestricted use, distribution, and reproduction in any medium, provided the original author and source are credited. 
Citation: Jawhari D, Alswisi M, Ghannam M, Al-Halman J (2016) Pharmacokinetic Comparison and Bioequivalence of a New Generic Formulation of Lenalidomide $25 \mathrm{mg}$ Capsules versus Revlimid in Healthy Volunteers under Fasting Conditions. J Bioequiv Availab 8: 214-219. doi: $10.4172 / j b b .1000298$

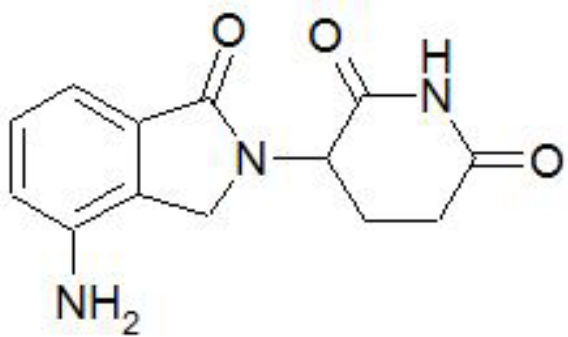

The empirical formula for lenalidomide is $\mathrm{C}_{13} \mathrm{H}_{13} \mathrm{~N}_{3} \mathrm{O}_{3}$, and the gram molecular weight is 259.3 [8].

Lenalidomide capsules are manufactured by Celgene under the trade name Revlimid'. Revlimid is available in the market in six dosage strengths containing lenalidomide $(2.5,5.0,10.0,15.0,20.0$, and 25.0 $\mathrm{mg})$.

Lenalidomide is soluble in organic solvent/water mixtures, and buffered aqueous solvents. Lenalidomide is more soluble in organic solvents and low $\mathrm{pH}$ solutions. Solubility was significantly lower in less acidic buffers, ranging from about $0.4-0.5 \mathrm{mg} / \mathrm{mL}$ [8].

According to the Biopharmaceutical Classification System (BCS), lenalidomide can be classified as a class III drug (highly soluble, low permeable) [10]. In this class of compounds, the absorption rate limiting step is the permeability of the drug substance rather than the rate of dissolution of the drug formulation.

Lenalidomide has proven clinical efficacy and it is indicated in a range of hematological malignancies including: relapsed and/ or refractory multiple myeloma (MM) [11] in combination with dexamethasone; myelodysplastic syndromes associated with del (5q); [12,13] and relapsed or refractory mantle cell lymphoma [14]. Lenalidomide has a predictable and manageable tolerability profile, with minimal neurotoxicity, allowing long-term administration $[9,15]$.

Lenalidomide is currently licensed in Europe (approved 2008), the USA (approved 2006), and many other countries, in combination with dexamethasone for the treatment of patients with relapsed and refractory multiple myeloma (RRMM) who have received at least one prior therapy $[5,16]$. In the USA (approved 2005) and Switzerland, lenalidomide is also approved for the treatment of transfusiondependent anemia in patients with Low- or Intermediate-1-risk myelodysplastic syndromes (MDS) with del (5q), with or without additional cytogenetic abnormalities [8,17]. In 2013, FDA has approved lenalidomide capsules for the treatment of patients with mantle cell lymphoma (MCL) whose disease has relapsed or progressed after two prior therapies, one of which included bortezomib [18].

Standard initial clinical doses of lenalidomide are $10 \mathrm{mg} /$ day for the treatment of MDS and $25 \mathrm{mg} /$ day for patients with RRMM $[4,8]$. Lenalidomide is also under clinical evaluation for the treatment of newly diagnosed multiple myeloma (MM) [19] and is being investigated in other indications such as chronic lymphocytic leukemia [20], acute myeloid leukemia (AML) [5], and certain aggressive and indolent types of non-Hodgkin lymphoma and certain solid tumors [19].

Multiple myeloma (MM) is a neoplastic disorder, characterized by accumulation of clonal plasma cell in the bone marrow and represents $10 \%$ of hematological malignancies. Presenting symptoms are anemia, fatigue, bone pain, hypercalcemia, renal insufficiency, recurrent infections, and neuropathy [9].

Lenalidomide has dual effects, involving both direct tumoricidal properties and immunomodulatory activity, which may result in rapid and sustained control of MM, respectively [21].

\section{Pharmacokinetics}

The pharmacokinetics of lenalidomide in healthy subjects are characterized by rapid oral absorption [7], time to reach maximum serum concentration $\left(\mathrm{T}_{\max }\right)$ of $0.77-1.0 \mathrm{~h}$ in healthy volunteers [19] and $1.19 \mathrm{~h}$ (standard deviation 0.55 ) in patients with AML after oral administration for $25 \mathrm{mg}$ [21]. Co-administration with food does not change the drug exposure, calculated as area under the curve (AUC), but reduces maximum serum concentration $\left(\mathrm{C}_{\max }\right)$ [5]. However, in the pivotal multiple myeloma registration trials conducted for the establishment of the efficacy and safety, lenalidomide was administered without regard to food intake [22].

Thus, lenalidomide can be administered with or without food.

Pharmacokinetics of lenalidomide is linear in both healthy volunteers and in patients with normal renal function. $\mathrm{C}_{\max }$ and AUC increased dose proportionally to doses up to $400 \mathrm{mg}$ [19]. There is no drug accumulation with multiple dosing [19]. The elimination half-life $\left(\mathrm{t}_{1 / 2}\right)$ was approximately $3 \mathrm{~h}$ in healthy subjects and $3.89 \mathrm{~h}$ in AML patients after oral administration of $25 \mathrm{mg}$ [21]. Lenalidomide is primarily renally eliminated with $90 \%$ of the dose was excreted unchanged in urine minimal amounts excreted in feces (4\%) [19]. Renal dysfunction reduces the clearance and prolongs the half-life of lenalidomide [7].

Lenalidomide is not subject to oxidative metabolism by cytochrome P450 (CYP)-2 [9]. Lenalidomide is a weak substrate of Pglycoprotein, but not a substrate of human organic anion transporters (OAT) $1 / 3$, human organic cationic transporter (OCT) 1, and human organic anion transporting polypeptide (OATP) 2 [9]. Lenalidomide undergoes hydrolysis in human plasma, with an in vitro half-life of approximately $8 \mathrm{~h}$, due to hydrolytic cleavage of glutarimide amide bonds [19]. A pharmacokinetic analysis showed the presence in low concentrations (1-5\%) of two metabolites in blood and urine, 5-OH-lenalidomide and $\mathrm{N}$-acetyl-lenalidomide [19].

Following a single oral dose of racemic lenalidomide, the enantiomeric ratio of S- and R-lenalidomide in plasma was stable from $1 \mathrm{~h}$ post-dose to the time of last detectable concentration. The R- and S-enantiomers of plasma lenalidomide averaged approximately $45 \%$ and $55 \%$ of the total drug, respectively, irrespective of dose levels in plasma [4].

The plasma protein binding of lenalidomide is $23 \%$ and $29 \%$ in multiple myeloma patients and healthy volunteers, respectively [22].

The aim of this study was to compare the bioavailability of two formulations of lenalidomide capsules $25 \mathrm{mg}$. A generic formulation developed at Hikma Pharmaceuticals PLCand a reference one (Revlimid, Celgene, United Kingdom), after a single dose administration of $25 \mathrm{mg}$ capsules to healthy volunteers under fasting condition.

\section{Materials and Methods}

\section{Ethics}

This study was only commenced after a written approval obtained by the Ethics Review Board (ERB), Optimum Clinical Research Inc. 
Citation: Jawhari D, Alswisi M, Ghannam M, Al-Halman J (2016) Pharmacokinetic Comparison and Bioequivalence of a New Generic Formulation of Lenalidomide 25 mg Capsules versus Revlimid in Healthy Volunteers under Fasting Conditions. J Bioequiv Availab 8: 214-219. doi: $10.4172 / j b b .1000298$

This research was carried out in accordance with the current Food and Drug Administration (FDA)guidance documents [23], Good Clinical Practice (GCP) as set out by the International Conference on Harmonization ( $\mathrm{ICH}$ ) and the basic principles defined in the U.S. Code of Federal Regulations (21 CFR Part 312) and the World Medical Association Declaration of Helsinki (Brazil, October 2013). The Clinical Trial Application for the study was reviewed by Health Canada and the study drug was not administered until the 'No Objection Letter (NOL)' had been received.

Volunteers were informed about the study procedure and signed the informed consent form. The code that was assigned to the protocol of the study was 2016-4039. Hikma Pharmaceuticals ensured that the investigational product was manufactured in accordance with GMP; the labeling also complied with the international regulatory requirements.

\section{Drugs}

The reference product was Revlimid $25 \mathrm{mg}$ hard gelatin capsules for Celgene, United Kingdom (batch number: A0567BA, expiry date: 07/2017). The test product was lenalidomide $25 \mathrm{mg}$ hard gelatin capsule (Batch Number 2151104, expiry date: 11/2017) developed by Hikma Pharmaceuticals PLC, manufactured 11/2015.

\section{Subjects}

Twenty four subjects were enrolled in this study, and all of them completed the study. The study population consisted of healthy, nonsmoking, male volunteers all within the (18-55 years) age group.

Lenalidomide is structurally related to thalidomide, which is a known human teratogenic substance that causes severe life-threatening birth defects. Due to the expected teratogenic effects of lenalidomide, the substance is contraindicated during pregnancy [22]. Therefore, only male subjects were enrolled into the study.

Literature data indicate a coefficient of variation (CV) for lenalidomide $\mathrm{C}_{\max }$ of approximately $15 \%$. The study subject number was powered to a $90 \%$ probability of meeting the $90 \%$ confidence interval for the treatment means assuming a $15 \%$ intra-subject variability and a difference between the treatment means of $7.5 \%$ or less. The calculated number of subjects was 20 and four (4) extra subjects were included into the study to account for potential dropouts bringing the total number to 24 subjects.

All subjects were selected subject to the inclusion and exclusion criteria. They were healthy according to medical history, physical examination (including vital signs) and laboratory tests (hematology, biochemistry, and urinalysis). Also, all volunteers were negative regarding HIV, Hepatitis B and Hepatitis $C$ tests as well as negative screening of ethyl alcohol and drugs of abuse in urine. All volunteers were healthy non-smoking, 18-55 years of age with a body mass index (BMI) greater than or equal to 19 and below $30 \mathrm{~kg} / \mathrm{m}^{2}$.

Enrolling healthy subjects in this study is complying with the current FDA bioequivalence recommendation [24], as well as Current European Medicines Agency (EMEA) guidance documents [25].

\section{Study design and blood sampling}

This study was an open-label, single-dose, randomized, two-period, two-treatment, two-sequence, crossover, comparative bioavailability study. Subjects were randomly assigned to one treatment sequence according to a predetermined computer-generated randomization scheme (procedure PLAN in SAS ${ }^{\circ}$ ). Subjects were assigned consecutive subject numbers in an ascending order. Each number identified a subject and determined the sequence of drug product administration according to the randomization scheme.

Subjects were confined in the clinical facility from $10 \mathrm{~h}$ prior to drug administration until at least $14 \mathrm{~h}$ post-dose.

In each period a single $25 \mathrm{mg}$ dose of lenalidomide hard gelatin capsule was orally administrated with about $240 \mathrm{ml}$ of water. The volunteers were asked to be fasting overnight for $10 \mathrm{~h}$. Subjects remained seated for at least the first $4 \mathrm{~h}$ following each drug administration. In each study period eighteen blood samples were collected prior to dosing $(0 \mathrm{~h})$ and at $0.167,0.333,0.5,0.75,1,1.25,1.5,1.75,2,2.5,3,4,6$, $8,10,12$, and $14 \mathrm{~h}$ after drug administration. The pre-dose sample was collected within 60 minutes prior to dosing. All attempts were made to collect post-dose blood samples within one minute from the scheduled sampling time. The actual clock time of each sample collection was recorded.

The drug administrations were separated by 7 calendar days. Urine drug and ethyl alcohol screening were performed at the screening phase of the study. Hematology and biochemistry tests were repeated after the collection of the last blood sample of the study. Safety was evaluated through the assessment of adverse events, and laboratory tests. All adverse events that occurred during the study were documented. Subjects were questioned about any symptoms or unexpected occurrences during the study. All adverse events, regardless of severity or relationship to the study drug, were recorded in the case report forms.

\section{Drug assay}

Plasma concentrations of lenalidomide in subject samples were measured according to a liquid chromatographic (LC) tandem mass spectrometric detection (MS/MS) achiral method developed and validated at the Bioanalytical Laboratory of Pharma Medica Research Inc. The analytical method procedures comply with the FDA guidance for industry: Bioanalytical method validation (May 2001).

The method involved liquid/liquid extraction. The standard calibration range was from 2.00 to $1000 \mathrm{ng} / \mathrm{mL}$ using a plasma sample volume of $0.100 \mathrm{~mL}$. Plasma samples were extracted under acidic conditions with a mixture of organic solvents; the organic phase was dried, reconstituted and transferred for LC-MS/MS analysis. Sample analysis was conducted using reversed phase chromatography. Lenalidomide was analyzed in the mass spectrometer SCIEX API 4000 using positive ion scan mode with a parent-daughter transition of 260-149. Similarly, the internal standard was analyzed using a parent-daughter transition of 264-152. The expected retention time for lenalidomide and the internal standard is approximately 0.8 minutes. Although the retention time of both lenalidomide and the internal standard is the same, the MS/MS technique allows distinguishing between the two molecules for quantitation, because they have different parent-daughter transitions.

\section{Pharmacokinetic parameters and statistical analysis}

A non-compartmental model was used to determine the pharmacokinetic parameters of lenalidomide. The main pharmacokinetic parameters of interest for this study were $\mathrm{C}_{\max }$, $\mathrm{AUC}_{0-\mathrm{T}}$ and $\mathrm{AUC}_{0-\infty}$. Other parameters such as $\mathrm{T}_{\max }, \mathrm{K}_{\mathrm{el}}$ and $\mathrm{T}_{1 / 2 \mathrm{el}}$ were provided for information purposes only. Pharmacokinetic parameters were estimated for lenalidomide using a non-compartmental approach in SAS (Statistical Analysis System). The natural logarithmic 
Citation: Jawhari D, Alswisi M, Ghannam M, Al-Halman J (2016) Pharmacokinetic Comparison and Bioequivalence of a New Generic Formulation of Lenalidomide 25 mg Capsules versus Revlimid in Healthy Volunteers under Fasting Conditions. J Bioequiv Availab 8: 214-219. doi: $10.4172 / j b b .1000298$

transformation of $\mathrm{C}_{\max }, \mathrm{AUC}_{0-\mathrm{T}}$ and $\mathrm{AUC}_{0-\infty}$ was used for all statistical inference.

Statistical analysis was performed on quality assured data from subjects in the statistical dataset. The PROC GLM procedure from SAS was used. The GLM procedure uses the method of least squares to fit general linear models. PROC GLM handles models relating one or several continuous dependent variables to one or several independent variables. The independent variables can be either classification variables, which divide the observations into discrete groups, or continuous variables. Thus, the GLM procedure can be used for many different analyses.

Analysis of variance (ANOVA) was performed on log-transformed $\mathrm{AUC}_{0-\mathrm{T}}, \mathrm{AUC}_{0-\infty}$ and $\mathrm{C}_{\max }$ and on untransformed $\mathrm{T}_{\max }, \mathrm{K}_{\mathrm{el}}$ and $\mathrm{T}_{1 / 2 \mathrm{el}}$ parameters. The significance of the sequence, period, treatment and subject-within-sequence effects was tested.

Using the same statistical model, the least-squares-means, the differences between the treatments least-squares-means and the corresponding standard errors of these differences were estimated for log-transformed $\mathrm{AUC}_{0-\mathrm{T}}, \mathrm{AUC}_{0-\infty}$ and $\mathrm{C}_{\max }$ parameters. Based on these statistics, the ratios of the geometric means for treatments and the corresponding $90 \%$ confidence intervals were calculated.

\section{Results}

The bioequivalence study was conducted in 24 healthy volunteers. Demographic characteristics (mean [SD]) for the overall group included in the study is shown in Table 1 as follows.

Under fasting conditions, $\mathrm{C}_{\max }, \mathrm{T}_{\max }, \mathrm{AUC}_{0-\mathrm{T}}$ and $\mathrm{AUC}_{0-\infty}$ for lenalidomide capsules $25 \mathrm{mg}$ and Revlimid were similar in healthy adult volunteers. The mean plasma concentrations versus time (pharmacokinetic) profiles were superimposed on each other (Figure 1). The mean parameters tested $\mathrm{C}_{\max }, \mathrm{T}_{\max }, \mathrm{AUC}_{0-\mathrm{T}}$ and $\mathrm{AUC}_{0-\infty}$ were similar for both formulations (Tables 2 and 3).

24 subjects were enrolled and completed the study. There was no significant deviation or adverse event that could affect the pharmacokinetic profile.

There was 5 AEs affecting 5 subjects in the study as follows: $3 \mathrm{AE}$ affecting 3 (12.5\%) subjects in Treatment A and 2 AEs affecting 2 (8.3\%) subjects in Treatment $\mathrm{B}$. The only AEs judged to be possibly related to any study drug were cough and headache following Treatment A (Test Product) and B (Reference Product) administration, respectively. All AEs were judged to be mild in severity.

\section{Discussion}

Two drug products are considered to be therapeutic equivalents and thus suitable for substitution (generic equivalents) if, among other factors, they are both pharmaceutical equivalents and bioequivalent. Two Drug products are considered pharmaceutical equivalents if they contain the same active ingredient(s), are of the same dosage form, route of administration and are identical in strength or concentration. Two drug products (of the same active ingredient) are considered bioequivalent when the rate and extent of biologic absorption of the active ingredients is essentially similar when administered at the same molar dose of the therapeutic ingredient under similar experimental conditions in either a single dose or multiple doses. Area under the curve (AUC) is accepted as a good indicator of extent of absorption, whereas $\mathrm{C}_{\max }$ and $\mathrm{T}_{\max }$ are considered estimators of the rate of absorption. Two internationally recognized organizations (U.S. Food and Drug Administration and European Medicines Agency) have proposed that bioequivalence can only be assumed when the characteristic parameters of bioavailability show no more than a defined difference, which depends on the nature of the drug, the subject population, and the clinical end point.

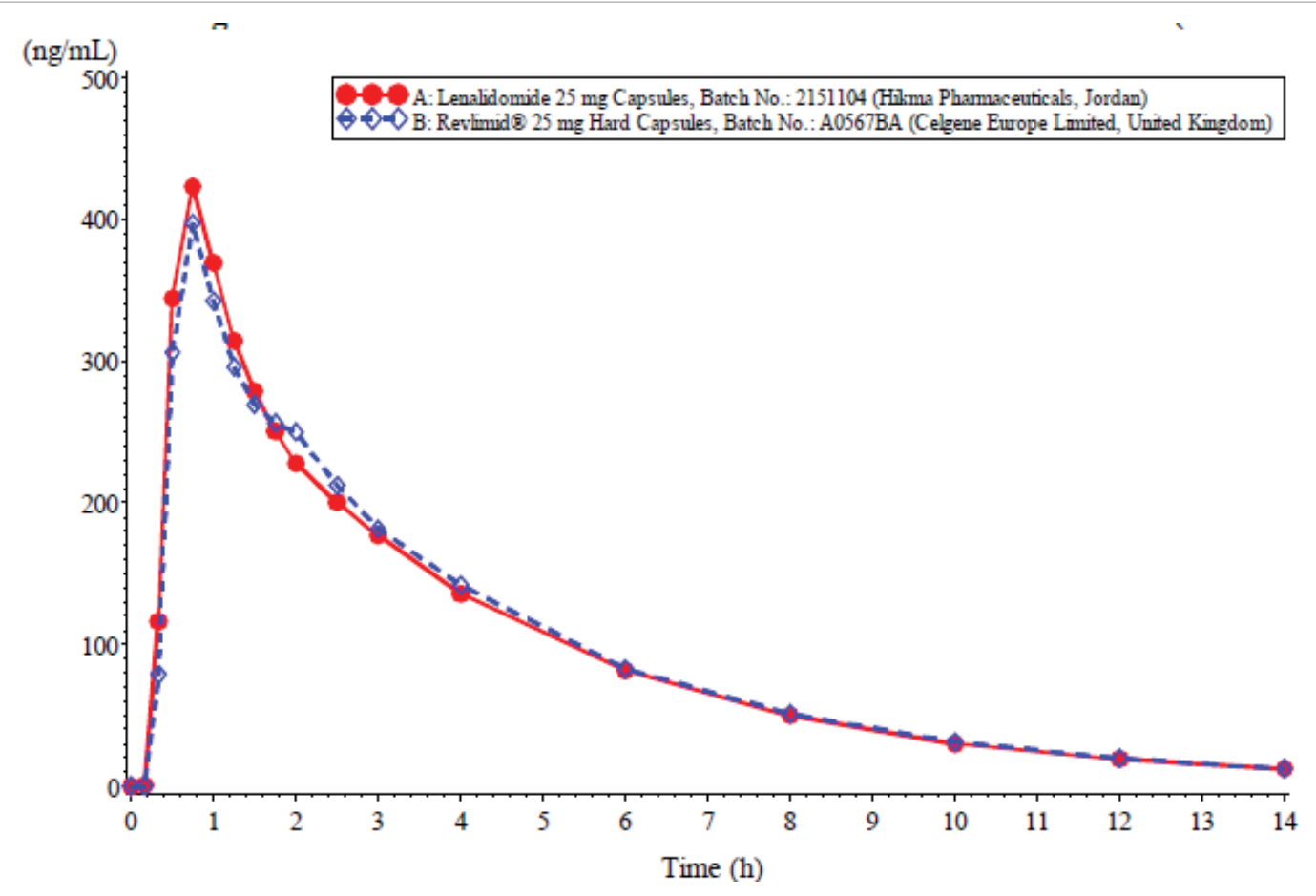

Figure 1: Plasma concentrations of lenalidomide capsule $25 \mathrm{mg}$ (Test) and Revlimid (Reference). 
Citation: Jawhari D, Alswisi M, Ghannam M, Al-Halman J (2016) Pharmacokinetic Comparison and Bioequivalence of a New Generic Formulation of Lenalidomide 25 mg Capsules versus Revlimid in Healthy Volunteers under Fasting Conditions. J Bioequiv Availab 8: 214-219. doi: $10.4172 / j b b .1000298$

\begin{tabular}{|c|c|c|}
\hline \multicolumn{2}{|c|}{ Demographic Characteristic } & \multirow{2}{*}{ 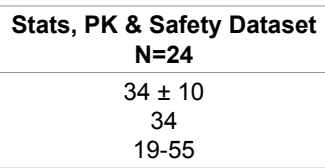 } \\
\hline Age (years) & $\begin{array}{c}\text { Mean } \pm \text { SD } \\
\text { Median } \\
\text { Range }\end{array}$ & \\
\hline Age Group & $\begin{array}{c}<18 \\
18-40 \\
41-64 \\
65-75 \\
>75\end{array}$ & $\begin{array}{c}0(0.0 \%) \\
19(79.2 \%) \\
5(20.8 \%) \\
0(0.0 \%) \\
0(0.0 \%)\end{array}$ \\
\hline Sex & $\begin{array}{c}\text { Male } \\
\text { Female }\end{array}$ & $\begin{array}{c}24(100.0 \%) \\
0(0 \%)\end{array}$ \\
\hline Race & $\begin{array}{l}\text { Asian } \\
\text { Black } \\
\text { White } \\
\text { Other }\end{array}$ & $\begin{array}{c}3(12.5 \%) \\
10(41.7 \%) \\
10(41.7 \%) \\
1(4.2 \%)\end{array}$ \\
\hline Ethnicity & Hispanic/Latino & $6(25.0 \%)$ \\
\hline BMI $\left(\mathbf{k g} / \mathrm{m}^{2}\right)$ & $\begin{array}{c}\text { Mean } \pm \text { SD } \\
\text { Median } \\
\text { Range }\end{array}$ & $\begin{array}{c}25.8 \pm 2.2 \\
25.6 \\
22.2-29.9\end{array}$ \\
\hline
\end{tabular}

Table 1: Demographic characteristics (mean [SD]) for the overall group included in the study.

\begin{tabular}{|c|c|c|c|c|}
\hline \multirow{2}{*}{ Parameter } & \multicolumn{2}{|c|}{ Test } & \multicolumn{2}{|c|}{ Reference } \\
\hline & Arithmetic Mean & CV\% & Arithmetic Mean & CV\% \\
\hline Peak Plasma Concentration: $\mathrm{C}_{\max }(\mathrm{ng} / \mathrm{mL})$ & 467.1 & 21 & 454.3 & 27 \\
\hline Time to reach $\mathrm{C}_{\max }: \mathrm{T}_{\max }$ (hours) & 0.75 & N.A & 0.75 & N.A \\
\hline $\begin{array}{l}\text { Area under the plasma concentration-time curve from } 0 \text { to } 14 \text { hours: } \mathrm{AUC}_{0-\mathrm{T}} \\
\qquad(\mathrm{ng} \cdot \mathrm{h} / \mathrm{mL})\end{array}$ & 1395.4 & 12 & 1396.3 & 13 \\
\hline AUC from time zero to infinity: $\mathrm{AUC}_{0-\infty}(\mathrm{ng} \cdot \mathrm{h} / \mathrm{mL})$ & 1448.7 & 13 & 1448.1 & 13 \\
\hline
\end{tabular}

Table 2: The pharmacokinetic parameters of lenalidomide capsules $25 \mathrm{mg}$ versus Revlimid.

\begin{tabular}{|c|c|c|c|c|c|c|}
\hline \multirow{2}{*}{ Parameter } & \multirow{2}{*}{ Intra-Subject C.V. (\%) } & \multicolumn{2}{|c|}{ Geometric LS Means } & \multirow{2}{*}{ Ratio (\%) } & \multicolumn{2}{|c|}{$90 \%$ Confidence Limits } \\
\hline & & Test & Reference & & Lower & Upper \\
\hline $\mathrm{C}_{\max }(\mathrm{ng} / \mathrm{mL})$ & 22 & 456.9 & 437.6 & 104.4 & 93.7 & 116.3 \\
\hline $\mathrm{AUC}_{0-\mathrm{T}}(\mathrm{ng} \cdot \mathrm{h} / \mathrm{mL})$ & 5 & 1385.8 & 1385.4 & 100.0 & 97.8 & 102.3 \\
\hline $\mathrm{AUC}_{0-\infty}(\mathrm{ng} \cdot \mathrm{h} / \mathrm{mL})$ & 4 & 1437.3 & 1435.6 & 100.1 & 97.9 & 102.4 \\
\hline
\end{tabular}

Table 3: Comparison of results with standards for bioequivalence.

\begin{tabular}{|c|c|c|c|c|}
\hline Parameter & $\begin{array}{l}\text { Lenalidomide } 25 \mathrm{mg} \text { capsule } \\
\text { (Hikma Study) }(\mathrm{n}=24)^{\star *}\end{array}$ & $\begin{array}{l}\text { Revlimid } 25 \text { mg capsule (Hikma } \\
\text { study) } \\
(n=24)^{\star *}\end{array}$ & $\begin{array}{l}\text { Lenalidomide } 25 \mathrm{mg} \text { oral } \\
\text { suspension dose }(n=6)^{*} \\
{[19]}\end{array}$ & $\begin{array}{l}\text { Lenalidomide } 25 \mathrm{mg} \text { dose } \\
\qquad(\mathrm{n}=14)^{* *}[26]\end{array}$ \\
\hline $\mathrm{C}_{\max }(\mathrm{ng} / \mathrm{mL})$ & $456.9(21)$ & $437.6(27)$ & $413 \pm 77$ & $367(26.3)$ \\
\hline $\mathrm{T}_{\max }$ (hours) & 0.75 & 0.75 & 1.00 & 1.00 \\
\hline $\mathrm{AUC}_{0-\mathrm{T}}(\mathrm{ng} \cdot \mathrm{h} / \mathrm{mL})$ & $1385.8(12)$ & $1385.4(13)$ & $1248 \pm 133$ & $1288(12.1)$ \\
\hline$A \cup C_{0-\infty}(n g \cdot h / m L)$ & $1437.3(13)$ & $1435.6(13)$ & $1319 \pm 162$ & $1361(12.7)$ \\
\hline
\end{tabular}

${ }^{*}$ Mean $\pm \mathrm{SD} ;{ }^{* \star}$ Mean $(\mathrm{CV} \%)$

Table 4: Pharmacokinetic parameters comparison between Hikma study and data reported in literature.

In this study, we investigated and compared the pharmacokinetics of two lenalidomide $25 \mathrm{mg}$ hard gelatin capsules formulations in healthy male volunteers (the first one is the reference product Revlimid and the second one is a test formulation developed by Hikma Pharmaceuticals). The observed parameters were in agreement with the values reported in the literature as shown in Table 4.

The rate and extent of absorption of the test drug do not show a significant difference from the rate and extent of absorption of the reference drug;

The ratios of LSM and $90 \%$ confidence intervals for the pharmacokinetic parameters $\left(\mathrm{C}_{\max }, \mathrm{AUC}_{0-\mathrm{T}}\right.$ and $\left.\mathrm{AUC}_{0-\infty}\right)$ of lenalidomide capsules $25 \mathrm{mg}$ versus Revlimid capsules $25 \mathrm{mg}$ under fasting conditions were within 80 to $125 \%$ FDA acceptance range for generic drug bioequivalence. The pharmacokinetics of the two formulations tested was similar with no significant adverse effects recorded for either.

\section{Conclusion}

Based on statistical results, it can be concluded that both products tested in this study satisfy with regulatory requirements of bioequivalence. Accordingly Hikma's, test product can be considered 
Citation: Jawhari D, Alswisi M, Ghannam M, Al-Halman J (2016) Pharmacokinetic Comparison and Bioequivalence of a New Generic Formulation of Lenalidomide $25 \mathrm{mg}$ Capsules versus Revlimid in Healthy Volunteers under Fasting Conditions. J Bioequiv Availab 8: 214-219. doi: $10.4172 / j b b .1000298$

interchangeable with Celgene's reference listed drug and both are expected to exhibit similar biopharmaceutical (or pharmacological or pharmacodynamics) performance. In addition Hikma's test product was well tolerated with no significant adverse effects as was the Reference product Revelimid.

\section{Acknowledgment}

All authors are employees of Hikma Pharmaceuticals Plc., which is the sponsor of the Bioequivalence study for lenalidomide $25 \mathrm{mg}$ capsules. The authors wish to acknowledge the support of Hikma Pharmaceuticals Research and Development Department-Oncology Team.

\section{References}

1. Verhelle D, Corral LG, Wong K, Mueller JH, Moutouh-de Parseval L, et al (2007) Lenalidomide and CC-4047 inhibit the proliferation of malignant B cells while expanding normal CD34+ progenitor cells. Cancer Res 67: 746-755.

2. Mitsiades N, Mitsiades CS, Poulaki V, Chauhan D, Richardson PG, et al. (2002) Apoptotic signaling induced by immunomodulatory thalidomide analogs in human multiple myeloma cells: therapeutic implications. Blood 99: 4525-4530.

3. Dredge K, Horsfall R, Robinson SP, Zhang LH, Ling Lu, et al. (2005) Orally administered lenalidomide (CC-5013) is anti-angiogenic in vivo and inhibits endothelial cell migration and Akt phosphorylation in vitro. Microvascular Research 69: 56-63.

4. Chen N, Kasserra C, Reyes J, Liu L, Lau H (2012) Single-dose pharmacokinetics of lenalidomide in healthy volunteers: dose proportionality, food effect, and racial sensitivity. Cancer Chemother Pharmacol 70: 717-725.

5. Chen Y, Borthakur G (2013) Lenalidomide as a novel treatment of acute myeloid leukemia. Expert Opin Investig Drugs 22: 389-397.

6. Zeldis JB, Knight RD, Jacques C, Tozer A, Bizzari JP (2010) Lenalidomide in multiple myeloma: current role and future directions. Expert Opinion on Pharmacotherapy 11: 829-842.

7. Chen N, Lau H, Kong L, Kumar G, Zeldis JB, et al. (2007) Pharmacokinetics of lenalidomide in subjects with various degrees of renal impairment and in subjects on hemodialysis. J Clin Pharmacol 47: 1466-1475.

8. www.revlimid.com

9. Bringhen S, Gay F, Pautasso G, Cerrato C, Boccadoro M, et al. (2012) Evaluation of the pharmacokinetics, preclinical, and clinical efficacy of lenalidomide for the treatment of multiple myeloma. Expert Opinion on Drug Metabolism \& Toxicology 8: 1209-1222.

10. FDA (2005) Clinical Pharmacology and Biopharmaceutics reviews.
11. Weber DM, Chen C, Niesvizky R, Wang M, Belch A, et al. (2007) Lenalidomide plus Dexamethasone for Relapsed Multiple Myeloma in North America. The New England Journal of Medicine 357: 2133-2142.

12. List A, Dewald G, Bennett J, Giagounidis A, Raza A, et al. (2006) Lenalidomide in the Myelodysplastic Syndrome with Chromosome $5 q$ Deletion. The New England Journal of Medicine 355: 1456-1465.

13. Fenaux P, Giagounidis A, Selleslag D, Rauzy OB, Mufti G, et al. (2011) Arandomized phase 3 study of lenalidomide versus placebo in RBC transfusiondependent patients with Low-/Intermediate-1-risk myelodysplastic syndromes with del5q. Blood 118: 3765-3776.

14. Ramchandren AR, Zhang L, Cicero S, Fu T, Thomas WE (2013) SingleAgent Lenalidomide in Patients With Mantle-Cell Lymphoma Who Relapsed or Progressed After or Were Refractory to Bortezomib: Phase II MCL-001 (EMERGE) Study. J Clin Oncol.

15. Dimopoulos MA, Terpos E, Niesvizky R (2013) How lenalidomide is changing the treatment of patients with multiple myeloma. Critical Reviews in Oncology/ Hematology 88: S23-S35.

16. Revlimid (Lenalidomide) summary of product characteristics. Celgene Europe Limited. Uxbridge, UK.

17. www.swissmedic.ch

18. http://www.fda.gov/Drugs/InformationOnDrugs/ApprovedDrugs/ucm355438.htm

19. Chen N, Wen L, Lau H, Surapaneni S, Kumar G (2012) Pharmacokinetics, metabolism and excretion of [14C]-lenalidomide following oral administration in healthy male subjects. Cancer Chemother Pharmacol 69: 789-797.

20. Galustian C, Dalgleish A (2009) Lenalidomide: a novel anticancer drug with multiple modalities. Expert Opin Pharmacother 10: 125-133.

21. Davies F, Baz R (2010) Lenalidomide mode of action: linking bench and clinical findings. Blood Rev 24 Suppl 1: S13-S19.

22. www.medicines.org.uk/emc/medicine/19841

23. Center for Drug Evaluation and Research (CDER) Food and Drug Administration (2003) Guidance for Industry-Bioavailability and Bioequivalence Studies for Orally Administered Drug Products-General Considerations.

24. www.fda.gov/downloads/drugs/guidancecomplianceregulatoryinformation/ guidances/ucm326798.pdf

25. www.ema.europa.eu/docs/en_GB/document_library/Scientific guideline/2015/10/WC500195125.pdf

26. Chen N, Weiss D, Reyes J, Liu L, Kasserra C, et al. (2014) No clinically significant drug interactions between lenalidomide and P-glycoprotein substrates and inhibitors: results from controlled phase I studies in healthy volunteers. Cancer Chemother Pharmacol 73: 1031-1039. 